\title{
Effect of oral contraceptives and/or metformin on GLP-1 secretion and reactive hypoglycaemia in polycystic ovary syndrome
}

\author{
Dorte Glintborg' ${ }^{1}$, Hanne Mumm ${ }^{1}$, Jens Juul Holst ${ }^{2}$ and Marianne Andersen ${ }^{1}$ \\ 1'Department of Endocrinology and Metabolism, Odense University Hospital, Odense C, Denmark \\ ${ }^{2}$ Department of Biomedical Sciences and NNF Centre for Basic Metabolic Research, The Panum Institute, \\ University of Copenhagen, Copenhagen, Denmark
}

\section{Endocrine CONNECTIONS

\begin{abstract}
Context: Insulin resistance in polycystic ovary syndrome (PCOS) may increase the risk of reactive hypoglycaemia $(\mathrm{RH})$ and decrease glucagon-like peptide-1 (GLP-1) secretion. The possible effects of treatment with oral contraceptives (OCP) and/or metformin on GLP-1 secretion and risk of RH in PCOS is undetermined.

Setting: Outpatient clinic.

Patients and interventions: Randomized, controlled clinical trial. Ninety women with PCOS were randomized to 12 -month treatment with OCP $(150 \mathrm{mg}$ desogestrel $+30 \mathrm{mg}$ ethinylestradiol), metformin ( $2 \mathrm{~g} /$ day) or metformin + OCP. Five-hour oral glucose tolerance tests (5-h OGTT) measuring fasting and area under the curve (AUC) for GLP-1, glucose, insulin and C-peptide were performed before and after the intervention period. Sixty-five women completed the study and 34 weight-matched healthy women were included as controls.

Main outcome measures: Changes in GLP-1, glucose, insulin and C-peptide during 5-h OGTT.

Results: Fasting GLP-1 levels increased during metformin + OCP vs OCP treatment, whereas AUC GLP-1 levels were unchanged during medical treatment. The prevalence of reactive hypoglycemia increased from $9 / 65$ to $14 / 65$ after intervention $(P<0.01)$ and was more common after treatment with metformin + OCP (increase from $3 / 23$ to $6 / 23$, $P=0.01$ ). Reactive hypoglycaemia was associated with higher insulin and C-peptide levels during 5-h OGTT, but was unassociated with BMI and AUC GLP-1. GLP-1 levels were comparable in PCOS vs controls. AUC GLP-1 levels were significantly lower in obese vs lean patients and were inversely associated with BMI.

Conclusions: AUC GLP-1 levels were unchanged during treatment. Increased risk of hypoglycemia during metformin $+\mathrm{OCP}$ could be associated with increased insulin secretion.
\end{abstract}

\author{
Key Words \\ - PCOS \\ - oral contraceptive \\ - metformin \\ - GLP-1 \\ - reactive hypoglycemia
}

Endocrine Connections (2017) 6, 267-277

\section{Introduction}

Polycystic ovary syndrome (PCOS) is characterized by oligo/anovulation, hyperandrogenaemia and polycystic ovaries $(1,2)$. Hyperinsulinaemia as a consequence of insulin resistance is present in most patients with PCOS (1). Incretin hormones are released after meal ingestion and account for up to $70 \%$ of postprandial insulin

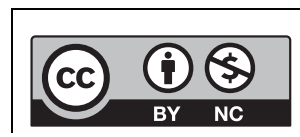

This work is licensed under a Creative Commons Attribution-NonCommercial 4.0 International License. 
secretion (3). Glucagon-like peptide-1 (GLP-1) and gastric inhibitory polypeptide are the most important incretin hormones. GLP-1 secretion is impaired in insulin resistant states such as obesity and type 2 diabetes (3), whereas results in patients with PCOS are conflicting $(4,5,6)$.

Reactive hypoglycaemia (RH) is defined as a drop in blood glucose levels $1 \frac{1 / 2}{2} 5 \mathrm{~h}$ after food consumption without indication of hypoglycaemia due to other causes (7). RH was prevalent in obese and lean patients with PCOS $(8,9)$ and was associated with insulin resistance and hyperinsulinaemia especially in obese patients (9). RH may contribute to the development of obesity by increasing appetite-evoking hormones such as leptin (10). Increased GLP-1 activity contributed to hypoglycemia after gastric bypass (11), but possible associations between RH and GLP-1 levels in PCOS have not been investigated.

Treatment modalities in PCOS aim at decreasing hyperandrogenism and improving insulin sensitivity along with weight loss $(12,13)$. Oral contraceptive treatment (OCP) regulates menstrual cycles and SHBG levels are increased, leading to decreased levels of free testosterone (14). OCP may increase body weight (15) and insulin resistance $(14,16)$, which could be associated with decreased GLP-1 levels. In contrast, animal studies suggested that estradiol and progesterone treatment could increase the effect and secretion of GLP-1 $(4,17)$. In one recent uncontrolled study, GLP-1 levels were unchanged during a meal tolerance test after 3 months of OCP treatment (ethinyl estradiol $30 \mu \mathrm{g} / \mathrm{drospirenone} 3 \mathrm{mg}$ ) in 14 lean patients with PCOS (4), but we are not aware of data in obese patients with PCOS. Increased insulin levels during OCP could be associated with increased risk of $\mathrm{RH}$ in PCOS, but no study tested this hypothesis.

Treatment with metformin improved insulin sensitivity and ovulatory function in PCOS (14), whereas androgen levels were only slightly decreased $(14,18)$. We recently reported a significant weight loss of $3.0 \mathrm{~kg}$ during 12-month metformin treatment (15). Decreased insulin levels during metformin treatment could be associated with decreased risk of RH and hence decreased appetite (9). Ghrelin levels decreased (19) and GLP-1 levels increased (6) after treatment with metformin in two uncontrolled studies in PCOS, which could have opposite effects on the risk of $\mathrm{RH}$, but we are not aware of controlled studies that investigated the effect of metformin on GLP-1 levels or risk of RH in PCOS.

The primary aim of the present study was to perform 5-h oral glucose tolerance tests (5-h OGTT) and evaluate the possible effects of treatment with OCP and/or metformin on GLP-1 levels and risk of RH in patients with PCOS.
Measures of GLP-1 secretion were furthermore compared in women with PCOS and weight-matched controls.

\section{Methods}

The methods of the present intervention study have been described recently in a paper regarding the effects of OCP and/or metformin treatment on body composition measures (15). Baseline data in patients and controls were reported in a paper on RH in PCOS (9). Two patients were excluded in (9) due to incomplete data, but were included in the present data as both patients completed study intervention.

\section{Patients}

Ninety white women aged 18-39 years with PCOS were included. The patients fulfilled the Rotterdam criteria for PCOS with minimum two of three of the following criteria: (1) Irregular periods during more than a year with a cycle length > 35 days; (2) total or free testosterone levels above reference interval (upper limits: total testosterone $>1.8 \mathrm{nmol} / \mathrm{L}$, free testosterone $>0.035 \mathrm{nmol} / \mathrm{L}$ ) and/or hirsutism and (3) transvaginal ultrasound with polycystic ovaries. Patients paused OCP for at least three months and metformin for at least one month before evaluation and were not treated with medicine known to affect hormonal or metabolic parameters. Patients randomized to metformin treatment alone consented to use barrier contraception during the study period or had an intrauterine device implanted.

\section{Exclusion criteria}

Patients with contraindications for OCP (obesity with $\mathrm{BMI} \geq 35 \mathrm{~kg} / \mathrm{m}^{2}$, previous or family history of thrombosis or breast cancer, coagulation defects and heavy smoking) and patients with diabetes (fasting plasma glucose $\geq 7.0 \mathrm{mmol} / \mathrm{L}$ and/or $\mathrm{HbA} 1 \mathrm{c} \geq 48 \mathrm{mmol} / \mathrm{mol}$ ), elevated liver enzymes, self-reported renal dysfunction, congestive heart disease, depression and eating disorders were excluded. Routine measurements included prolactin, total and free testosterone, TSH, 17-hydroxyprogesterone, liver enzymes, HbA1c, plasma glucose and electrolytes.

\section{Power calculation}

Previous short-term studies on metformin and OCP treatment in PCOS using area under the curve (AUC)

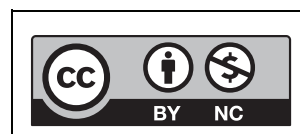

This work is licensed under a Creative Commons Attribution-NonCommercial 4.0 International License. 
for insulin during 2-h OGTT as the primary end point included a minimum of 15 patients in each group $(20,21)$. There was no published data on GLP-1 levels in PCOS by the time of study planning. It was therefore impossible to perform a power calculation on the effect of OCP and/or metformin treatment on GLP-1 levels and 30 patients were arbitrarily included in each treatment arm.

\section{Controls}

Thirty-four healthy white women matched to the group of women with PCOS regarding BMI and age were included. All controls had regular menstrual cycles and did not have hirsutism. Controls had paused OCP for at least three months prior to evaluation.

The study was approved by the local ethics committee (Region of Southern Denmark, study ID S-20070020) and by the Danish Medicines Agency, and all subjects gave written informed consent. The trial was registered at www.clinicaltrials.gov, registration number NCT00451568 (intervention study) and NCT01995773 (controls).

\section{Study protocol}

Patients were randomized to 12-month treatment with metformin (1+1g/day), OCP (150 mg desogestrel+30 mg ethinylestradiol) or combined treatment, metformin + OCP. Before the intervention, patients underwent physical examination including transvaginal ultrasound, fasting blood samples and 5-h OGTT. After 12-month medical treatment, the patients were admitted for repeated examinations similar to the initial evaluation program. Examinations were performed on a random cycle day. Safety tests were performed after 6 and 12 months and included weight, blood pressure, HbA1c, liver enzymes, electrolytes and white blood cell count. Pregnancy tests were performed by the participants each month.

\section{Clinical examination}

Clinical examination included Ferriman-Gallwey score, blood pressure, waist-to-hip ratio, height and weight.

\section{Fasting blood samples and 5-h OGTT}

A 5-h OGTT was performed after overnight fasting. GLP-1, capillary blood glucose (BG), insulin and C-peptide were measured at baseline (fasting) and at 30, $60,90,120,180,240$ and $300 \mathrm{~min}$ after oral ingestion of a glucose load containing the equivalent of $75 \mathrm{~g}$ anhydrous glucose dissolved in water. Homeostasis model assessment (HOMA-r) was calculated as fasting insulin $\times$ fasting $\mathrm{BG} / 22.5$. RH was defined as $\mathrm{BG}<3.3 \mathrm{mmol} / \mathrm{L}$ occurring between 120 and $300 \mathrm{~min}$ during the 5-h OGTT. Two and $5 \mathrm{~h}$ AUC for glucose, insulin and C-peptide during 5-h OGTT was calculated applying the trapezium rule.

\section{Assays}

We measured total GLP-1 levels, i.e. the sum of intact GLP-1 and the metabolite generated by dipeptidylpeptidase 4-mediated degradation, which is the relevant parameter for evaluation of secretion and potential actions of GLP-1 (22). GLP-1 concentrations were measured by radioimmunoassay after extraction of plasma with $70 \%$ ethanol (vol/vol, final concentration). The carboxyterminal GLP-1 immunoreactivity was determined using antiserum 89,390, which has an absolute requirement for the intact amidated carboxy-terminus of GLP-1 7-36-amide and cross-reacts less than $0.01 \%$ with carboxy-terminally truncated fragments and at least 89\% with GLP-1 9-36amide, the primary metabolite of dipeptidyl-peptidase 4-mediated degradation. The sum of the two components (total GLP-1 concentration) reflects the rate of secretion of the L-cell. The sensitivity was below $1 \mathrm{pmol} / \mathrm{L}$ and the intra-assay coefficient of variation (CV) was below 5\% (23). All samples were measured in the same period, using identical reagents and quality controls.

Total testosterone was analyzed using an in-house method based on the extraction of steroids from serum by ether, separation of extracted steroids by liquid chromatography and quantification by radioimmunoassay as previously described (24). In this method, testosterone, dihydrotestosterone and androstendione are extracted before applying radioimmunoassay and overestimation of testosterone levels is hereby avoided. The results of this method correlate closely with the determination of testosterone levels using mass spectrometry (25). SHBG was analyzed by time-resolved immunoassay using an AutoDELFIA commercial kit (Wallac Oy, Turku, Finland). Free Testosterone Index (FTI) was calculated from measurements of total testosterone and SHBG. The intraassay CV was 8.2 for total testosterone and 5.2\% for SHBG. The inter-assay CV was $13.8 \%$ for total testosterone and 7.5\% for SHBG.

Serum levels of insulin and C-peptide were analyzed by time-resolved fluoroimmunoassay using commercial AutoDELFIA, kits (PerkinElmer Life Sciences). The intraassay CV was $1.1-5.0 \%$ for C-peptide $1.1-5.0 \%$ and

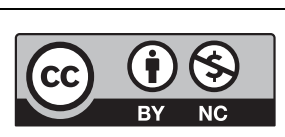

This work is licensed under a Creative Commons Attribution-NonCommercial 4.0 International License. 
$2.1-3.7 \%$ for insulin. The inter-assay CV was $1.1-3.4 \%$ for C-peptide and $3.4-4.0 \%$ for insulin.

\section{Ethics}

The study was approved by the local ethics committee (Region of Southern Denmark, study ID S-20070020) and by the Danish Medicines Agency and all subjects gave written informed consent.

\section{Statistical analysis}

Variables are presented as medians and quartiles. Pretreatment differences between included patients in the three treatment arms were tested using the KruskallWallis test followed by the Mann-Whitney $U$ test. The Mann-Whitney test was used to compare the differences between patients and controls and between subgroups of patients with PCOS.

Spearman bivariate associations were performed to evaluate associations between AUC GLP-1 and BMI.

Basal differences between patients randomized to the three different interventions and drop-out during follow-up were taken into account by comparing delta $(\Delta)$ values of hormonal and metabolic variables between the three intervention groups using the Kruskall-Wallis test followed by the Mann-Whitney $U$ test. Delta values were calculated as post-treatment level minus pre-treatment level of each analyzed variable.

All statistics were performed using SPSS 17.0 (SPSS). $P$ values $<0.05$ were considered significant.

\section{Results}

Of the 90 enrolled patients, 65 patients (72\%) completed the whole study period (Fig. 1), previously presented in (15). Patients randomized to the three treatment groups were comparable regarding all clinical and biochemical characteristics (Table 1).

\section{Effects of medical intervention}

Metformin vs OCP Changes in GLP-1 (fasting, AUC and 5-h OGTT) were comparable during metformin and OCP treatment, whereas treatment with metformin was followed by decreased weight, insulin (time points 120, 180, 240 and $300 \mathrm{~min}$ during 5-h OGTT) and C-peptide

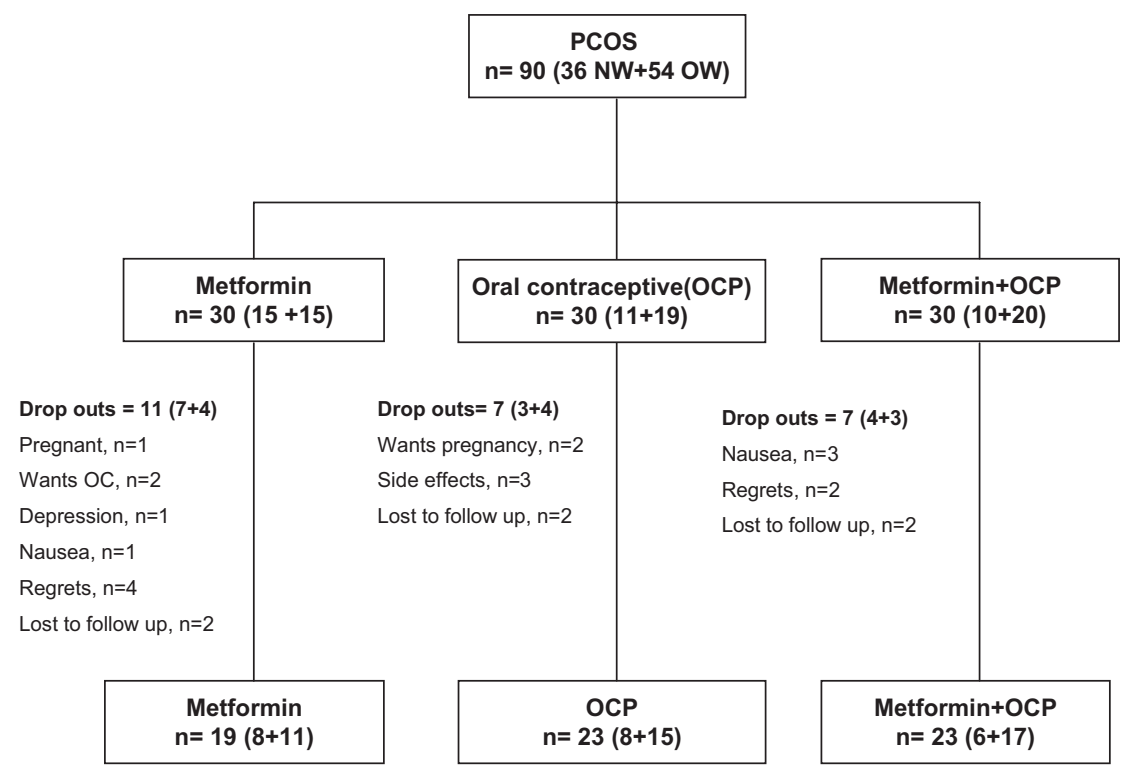

Data presented as number of participants (number of normal weight + overweight patients)

$\mathrm{OCP}=$ oral contraceptive treatment

NW: normal weight, BMI $<25 \mathrm{~kg} / \mathrm{m}^{2}$

OW: overweight, BMI $\geq 25 \mathrm{~kg} / \mathrm{m}^{2}$

Figure 1

Drop outs $\mathrm{NW}=14 / 36=38.8 \%$, drop outs $\mathrm{OW}=11 / 54=20.3 \%, \mathrm{p}=0.06$.

Flow chart of included and excluded subjects and study design.

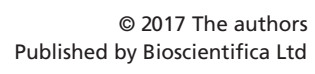

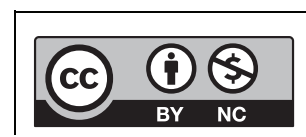

This work is licensed under a Creative Commons Attribution-NonCommercial 4.0 International License. 
Table 1 Baseline clinical and biochemical data in patients with PCOS completing medical intervention $(n=65)$.

Age (years)
Weight $(\mathrm{kg})$
BMI (kg/m²)
T-testosterone (nmol/L)
SHBG (nmol/L)
FTI
Fasting
GLP-1 (mmol/L)
Insulin (pmol/L)
C-peptide (pmol/L)
HOMA (mmol/L $\mathrm{nmol} / \mathrm{L})$
OGTT
$2 \mathrm{~h}$ AUC GLP-1 $\left(10^{2} \mathrm{mmol} / \mathrm{L} \times \mathrm{h}\right)$
$5 \mathrm{~h}$ AUC GLP-1 $\left(10^{2} \mathrm{mmol} / \mathrm{L} \times \mathrm{h}\right)$
$2 \mathrm{~h}$ AUC BG $\left(10^{2} \mathrm{mmol} / \mathrm{L} \times \mathrm{h}\right)$
$5 \mathrm{~h}$ AUC BG $\left(10^{2} \mathrm{mmol} / \mathrm{L} \times \mathrm{h}\right)$
$2 \mathrm{~h}$ AUC insulin $\left(10^{3} \mathrm{pmol} / \mathrm{L} \times \mathrm{h}\right)$
$5 \mathrm{~h}$ AUC insulin $\left(10^{3} \mathrm{pmol} / \mathrm{L} \times \mathrm{h}\right)$
$2 \mathrm{~h}$ AUC C-peptide $\left(10^{4} \mathrm{pmol} / \mathrm{L} \times \mathrm{h}\right)$
$5 \mathrm{~h}$ AUC C-peptide $\left(10^{4} \mathrm{pmol} / \mathrm{L} \times \mathrm{h}\right)$

\begin{tabular}{c}
\hline Metformin $(n=19)$ \\
\hline $31(24 ; 33)$ \\
$73.6(69.2 ; 83.5)$ \\
$25.9(24.1 ; 29.6)$ \\
$1.96(1.30 ; 2.88)$ \\
$44(32 ; 62)$ \\
$0.04(0.03 ; 0.05)$ \\
$8.5(6.9 ; 10.5)$ \\
$51(34 ; 71)$ \\
$611(467 ; 906)$ \\
$11.7(7.0 ; 19.8)$ \\
$19.8(16.7 ; 23.8)$ \\
$38.4(32.5 ; 47.4)$ \\
$9.2(8.3 ; 10.0)$ \\
$17.8(16.4 ; 19.5)$ \\
$39.8(30.1 ; 54.2)$ \\
$51.5(41.3 ; 77.4)$ \\
$25.8(22.0 ; 34.3)$ \\
$46.0(37.1 ; 66.6)$
\end{tabular}

\begin{tabular}{c}
\hline OCP $(n=23)$ \\
\hline $28(24 ; 32)$ \\
$86.0(62.1 ; 88.8)$ \\
$28.0(22.9 ; 31.8)$ \\
$1.65(1.39 ; 2.69)$ \\
$52(36 ; 82)$ \\
$0.03(0.02 ; 0.05)$ \\
\\
$9.5(7.5 ; 11.0)$ \\
$49(33 ; 75)$ \\
$564(458 ; 821)$ \\
$11.6(7.8 ; 17.0)$ \\
$19.7(14.6 ; 22.7)$ \\
$39.5(30.9 ; 43.9)$ \\
$8.5(8.0 ; 9.7)$ \\
$17.0(16.3 ; 18.7)$ \\
$44.7(30.0 ; 66.8)$ \\
$56.9(42.8 ; 92.8)$ \\
$28.3(22.2 ; 33.7)$ \\
$48.0(39.7 ; 61.4)$ \\
\hline
\end{tabular}

\begin{tabular}{c} 
Metformin + OCP $(n=23)$ \\
\hline $30(24 ; 31)$ \\
$80.2(70.5 ; 86.0)$ \\
$27.6(24.3 ; 31.2)$ \\
$1.60(1.26 ; 2.32)$ \\
$47(32 ; 72)$ \\
$0.03(0.02 ; 0.04)$
\end{tabular}

Data presented as median (25; 75 quartiles). No significant differences between groups (Kruskall-Wallis test). FG total, total Ferriman-Gallwey score; FTI, free testosterone index; OCP, oral contraceptive treatment.

(fasting and time points 180, 240 and 300 min during $5-\mathrm{h}$ OGTT and 5-h AUC) compared to OCP (Fig. 2 and Table 2).

Metformin + OCP vs OCP Treatment with metformin + OCP was associated with increased fasting GLP-1, whereas changes in AUC GLP-1 were comparable. Weight, insulin (fasting and time point $240 \mathrm{~min}$ during 5 -h OGTT) and fasting C-peptide decreased during metformin $+\mathrm{OCP}$ compared to OCP.

Metformin vs metformin + OCP Changes in GLP-1 (fasting, AUC and during 5-h OGTT) were comparable during metformin vs metformin $+\mathrm{OCP}$. Metformin treatment was followed by decreased weight, BMI, insulin (time points 180 and $300 \mathrm{~min}$ during 5-h OGTT) and C-peptide (fasting and at time points 180 and $240 \mathrm{~min}$ during 5-h OGTT) compared to changes during treatment with metformin + OCP.

\section{RH during medical intervention}

The prevalence of RH increased significantly from 9/65 to $14 / 65$ after study intervention $(P=0.01)$. The prevalence of RH during metformin+OCP increased significantly (from $3 / 23$ to $6 / 23, P=0.01$ ) and was unchanged during metformin (from $1 / 19$ to $3 / 19, P=0.16$ ) and during OCP (before and after $5 / 23$ ).

$$
\begin{aligned}
& \text { http://www.endocrineconnections.org } \\
& \text { DOI: 10.1530/EC-17-0034 }
\end{aligned}
$$

2017 The author Published by Bioscientifica Ltd
Patients with RH after study intervention were characterized by higher 2-h AUC insulin $(61.3(39.6 ; 80.4)$ vs $\left.40.0(28.3 ; 60.9) \times 10^{3} \mathrm{pmol} / \mathrm{L} \times \mathrm{h}\right)$ and 5 -h AUC insulin $\left(85.4(61.4 ; 106.7)\right.$ vs $\left.59.3(42.6 ; 97.8) \times 10^{3} \mathrm{pmol} / \mathrm{L} \times \mathrm{h}\right)$ at 12 months compared to patients without $\mathrm{RH}$, whereas fasting GLP-1 levels $(9.0(7.0 ; 11.0)$ vs 11.3 (9.3; 13.3) $\mathrm{mmol} / \mathrm{L}$ ) were lower. 2-h and 5-h AUC GLP-1, age and BMI were comparable in patients with and without $\mathrm{RH}$ (data not shown). In patients with BMI $\geq 25 \mathrm{~kg} / \mathrm{m}^{2}$, the prevalence of RH increased from $7 / 43$ to $10 / 43(P=0.04)$ and in normal-weight patients, the prevalence of $\mathrm{RH}$ increased from $2 / 22$ to $4 / 22(P=0.03)$ during medical intervention.

\section{Patients with PCOS vs controls and obese vs lean patients with PCOS}

GLP-1 GLP-1 levels (fasting and during $5 \mathrm{~h}$ OGTT) were comparable in patients vs controls (Table 3), in lean patients vs lean controls, and in obese patients vs obese controls (data not shown). GLP-1 levels were higher in lean vs obese patients (Fig. 3 and Table 4 ) and in lean vs obese controls (data not shown). Two-hour and 5-h AUC GLP-1 levels were inversely associated with BMI in patients with PCOS $(r=-0.31$ and $r=-0.34$, respectively, $P<0.004)$, but these associations were non-significant in controls (Tables 3 and 4).

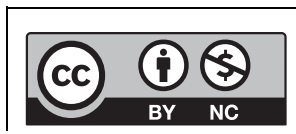

This work is licensed under a Creative Commons Attribution-NonCommercial 4.0 International License. 
Metformin

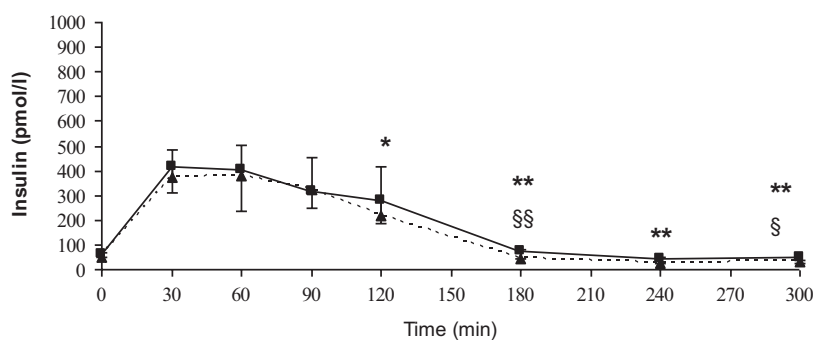

OCP
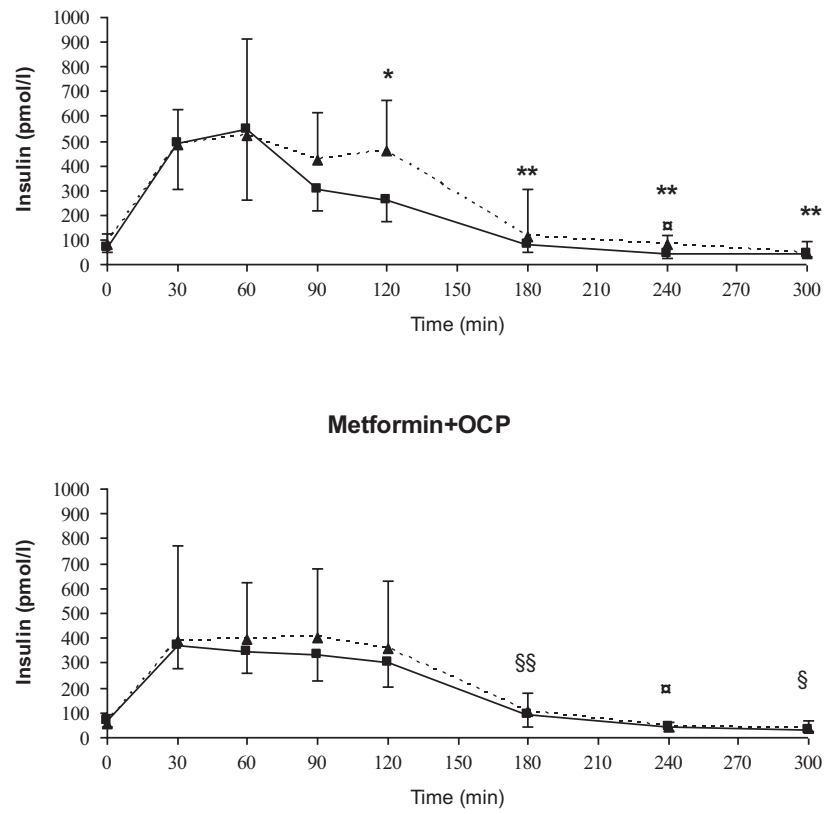

Squares: Before intervention, triangles: After intervention

Kruskall Wallis followed by Mann-Whitney test on delta values

Changes during metformin vs. changes during OCP: ${ }^{*} \mathrm{p}<0.05,{ }^{* *} \mathrm{p}<0.001$

Changes during metformin vs. changes during metformin + OCP: $\S p<0.05, \S \S p<0.001$

Changes during OCP vs. changes during metformin + OCP: $\propto p<0.05$

\section{Figure 2}

Insulin and C-peptide levels before and after intervention.

RH RH was found in $15 / 90$ (16.7\%) patients and 0 controls (9). Patients with $\mathrm{RH}$ had significantly higher fasting GLP-1 $8.0(6.0 ; 10.0) \mathrm{mmol} / \mathrm{L}$ vs patients without RH $7.0(9.5 ; 11.0) \mathrm{mmol} / \mathrm{L}, \mathrm{P}<0.04$. GLP-1 levels during 5 -h OGTT were comparable in patients with RH vs patients without RH. As recently presented, the presence of RH was independent of BMI (9), data not shown.

Insulin and C-peptide Women with PCOS had significantly higher levels of insulin (fasting, 2- and 5-h AUC) and C-peptide (fasting, 2- and 5-h AUC) vs controls

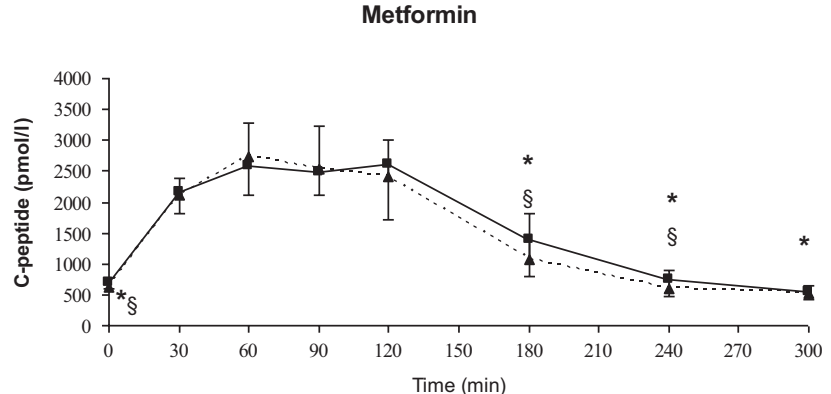

OCP

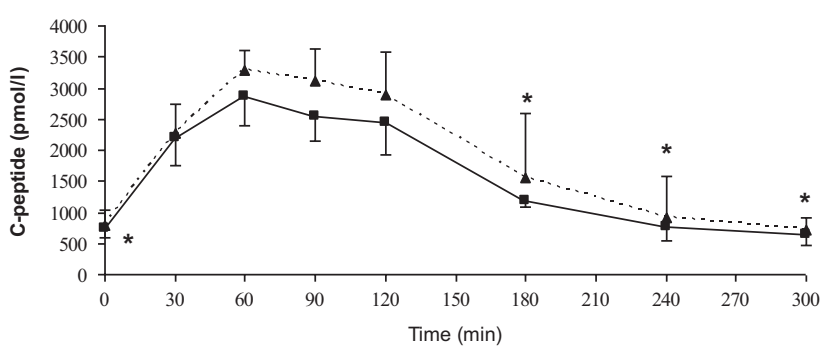

Metformin+OCP

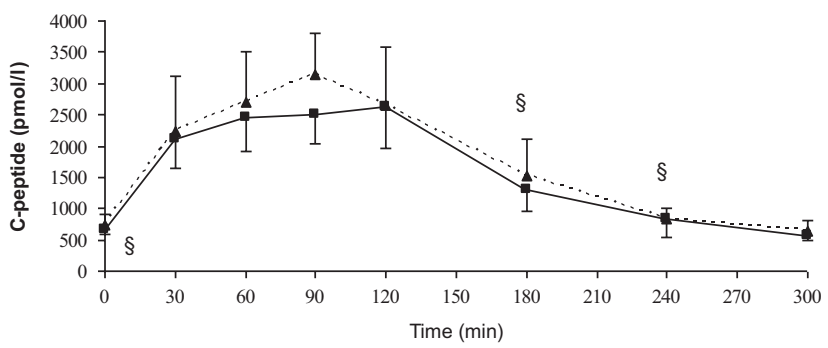

(Table 3). Obese patients with PCOS had significantly higher levels of insulin (fasting, 2- and 5-h AUC), C-peptide (fasting, 2- and 5-h AUC) and HOMA-IR compared to lean patients (Table 4 ).

\section{Discussion}

To our knowledge, this is the first long-term randomized controlled clinical trial examining the effect of OCP and/or metformin treatment on GLP-1 secretion and risk of RH in PCOS. Fasting GLP-1 levels and the risk of RH increased in

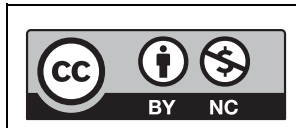

This work is licensed under a Creative Commons Attribution-NonCommercial 4.0 International License. 
Table 2 Median changes in clinical and biochemical variables during medical intervention.

Weight $(\mathrm{kg}) * *$
BMI $\left(\mathrm{kg} / \mathrm{m}^{2}\right)^{* *}$
T-testosterone (nmol/L)
SHBG (nmol/L)**
FTI**
Fasting
GLP-1 (mmol/L)*
Insulin (pmol/L)*
C-peptide $(\mathrm{pmol} / \mathrm{L}) *$
HOMA (mmol/L $\mathrm{nmol} / \mathrm{L})$
OGTT
2h AUC GLP-1 $\left(10^{2} \mathrm{mmol} / \mathrm{L} \times \mathrm{h}\right)$
$5 \mathrm{~h}$ AUC GLP-1 $\left(10^{2} \mathrm{mmol} / \mathrm{L} \times \mathrm{h}\right)$
$2 \mathrm{~h}$ AUC insulin $\left(10^{3} \mathrm{pmol} / \mathrm{L} \times \mathrm{h}\right)$
$5 \mathrm{~h}$ AUC insulin $\left(10^{3} \mathrm{pmol} / \mathrm{L} \times \mathrm{h}\right)$
$2 \mathrm{~h}$ AUC C-peptide $\left(10^{4} \mathrm{pmol} / \mathrm{L} \times \mathrm{h}\right)$
$5 \mathrm{~h}$ AUC C-peptide $\left(10^{4} \mathrm{pmol} / \mathrm{L} \times \mathrm{h}\right) *$

\begin{tabular}{c} 
Metformin $(n=19)$ \\
\hline$-3.0(-10.3 ; 0.6)^{\mathrm{a}}$ \\
$-1.0(-3.7 ; 0.2)^{\mathrm{a}}$ \\
$-0.35(-0.97 ;-0.06)$ \\
$9(-2.19)^{\text {aas }}$ \\
$-0.007^{a \S}(-0.019 ; 0.0036)$ \\
$2.5(0.3 ; 3.8)$ \\
$2(-22 ; 16)$ \\
$-86(-237 ; 78)^{\mathrm{a} \S}$ \\
$-0.2(-5.5 ; 4.1)$
\end{tabular}

$0.4(-2.9 ; 3.4)$

$3.2(-4.1 ; 7.0)$

$0.5(-13.0 ; 7.2)$

$1.0(-20.2 ; 8.7)$

$1.6(-42.3 ; 53.8)$

$0.8(-10.8 ; 5.4)^{\mathrm{a}}$

\begin{tabular}{c} 
OCP $(n=23)$ \\
\hline $1.2(-0.8 ; 3.0)$ \\
$0.4(-0.4 ; 1.2)$ \\
$-0.36(-1.17 ;-0.04)$ \\
$138(89 ; 162)$ \\
$-0.023(-0.034 ;-0.008)$ \\
$1.3(-1.0 ; 2.4)$ \\
$9(-6 ; 46)$ \\
$95(-73 ; 247)$ \\
$1.7(-1.1 ; 10.4)$
\end{tabular}

$-2.6(-1.7 ; 10.9)$

$0.3(-0.4 ; 1.0)$

$6.5(-5.3 ; 23.0)$

$13.1(-4.4 ; 54.9)$

$2.6(-3.2 ; 7.1)$

$8.7(-3.1 ; 18.6)$

Metformin + OCP $(n=23)$
$-1.9(-4.9 ; 0.1)^{\mathrm{a}}$
$-0.8(-1.8 ; 0.03) \mathrm{a}$
$-0.42(-1.19 ; 0.01)$
$106(59 ; 175)$
$-0.019(-0.029 ;-0.014)$

$3.0(1.4 ; 4.6) a$

$-8(-18 ; 6) \mathrm{a}$

$-97(-289 ; 43)^{\mathrm{a}}$

$-0.6(-5.1 ; 1.8)$

$1.7(-3.1 ; 8.9)$

$-0.2(-1.8 ; 2.3)$

$-0.3(-9.0 ; 12.3)$

$3.6(-11.5 ; 21.4)$

$0.8(-1.5 ; 10.0)$

$4.4(-1.6 ; 10.4)$

Data presented as median ( $25 ; 75 \%$ quartiles). The median changes in BG (fasting, $2 \mathrm{~h}$ and $5 \mathrm{~h}$ AUC) were comparable in the three intervention groups (data not shown).

${ }^{*} P<0.05,{ }^{* *} P<0.001$, Kruskall-Wallis test between groups; ${ }^{a} P<0.05$ vs OCP, Kruskall-Wallis test followed by Mann Whitney; ${ }^{\S} P<0.05$, ${ }^{\S \S} P<0.001$ vs metformin + OCP, Kruskall-Wallis test followed by Mann Whitney.

$\mathrm{FTI}$, free testosterone index; $\mathrm{OCP}$, oral contraceptive treatment.

patients treated with metformin + OCP, whereas changes in AUC GLP-1 levels were comparable between the medical intervention groups despite significant changes in insulin sensitivity, body weight and testosterone levels. Increased risk of $\mathrm{RH}$ after medical intervention was associated with increased insulin levels during 5-h OGTT and was not predicted by AUC GLP-1 or BMI.

Few previous studies evaluated GLP-1 secretion during medical intervention in women with PCOS. In agreement with our study, a recent uncontrolled study reported unchanged GLP-1 levels during a standardized meal test following 3 months treatment with a $4^{\text {th }}$ generation OCP (30 $\mu$ g ethinyl estradiol/3 mg drospirenone) in 14 lean patients with PCOS (4). Limited data are available on possible interactions between sex hormones and GLP-1. Treatment with GLP-1 increased LH secretion and induced puberty in female rats $(17,26)$. Increased LH in PCOS (27) could therefore be associated with higher GLP-1 levels. We found no association between testosterone and GLP-1 levels and GLP-1 levels were

Table 3 Baseline clinical and biochemical data in patients and controls.

\begin{tabular}{|c|c|c|}
\hline & $\operatorname{PCOS}(n=90)$ & Controls $(n=34)$ \\
\hline Age (years) & $28(24-32)$ & $26(22-32)$ \\
\hline Weight (kg) & $73.7(67.1 ; 85.3)$ & $71.9(67.6 ; 82.1)$ \\
\hline BMI $\left(\mathrm{kg} / \mathrm{m}^{2}\right)$ & $26.8(23.3-30.8)$ & $25.1(22.6-27.4)$ \\
\hline \multicolumn{3}{|l|}{ Fasting } \\
\hline GLP-1 (mmol/L) & $9.0(7.5 ; 10.9)$ & $8.3(7.0 ; 10.6)$ \\
\hline Insulin (pmol/L) & $71(50-95) *$ & $55(48-68)$ \\
\hline C-peptide (pmol/L) & $707(591-930) *$ & $631(561-727)$ \\
\hline HOMA (mmol/L nmol/L) & $16.1(11.7 ; 21.0)$ & $14.2(11.4 ; 16.5)$ \\
\hline \multicolumn{3}{|l|}{ OGTT } \\
\hline $2 \mathrm{~h}$ AUC GLP-1 (10² $\mathrm{mmol} / \mathrm{L} * \mathrm{~h})$ & $18.0(15.4 ; 22.7)$ & $18.1(16.1 ; 23.7)$ \\
\hline $5 \mathrm{~h}$ AUC GLP-1 (10² $\mathrm{mmol} / \mathrm{L} * \mathrm{~h})$ & $38.6(31.7 ; 44.4)$ & $37.0(34.5 ; 46.6)$ \\
\hline $2 \mathrm{~h} \mathrm{AUC} \mathrm{BG}\left(10^{2} \mathrm{mmol} / \mathrm{L} * \mathrm{~h}\right)$ & $8.9(8.3 ; 9.8)$ & $8.6(8.3 ; 9.3)$ \\
\hline $5 \mathrm{~h}$ AUC BG $\left(10^{2} \mathrm{mmol} / \mathrm{L}^{*} \mathrm{~h}\right)$ & $17.7(16.5 ; 19.1)$ & $18.5(17.6 ; 19.0)$ \\
\hline $2 \mathrm{~h}$ AUC insulin $\left(10^{3} \mathrm{pmol} / \mathrm{L} * \mathrm{~h}\right)$ & $41.3(30.7 ; 66.0) *$ & $34.1(22.9 ; 51.2)$ \\
\hline $5 \mathrm{~h}$ AUC insulin $\left(10^{3} \mathrm{pmol} / \mathrm{L} * \mathrm{~h}\right)$ & $60.8(44.7 ; 89.9) *$ & $48.3(33.3 ; 70.6)$ \\
\hline $5 \mathrm{~h}$ AUC C-peptide $\left(10^{4} \mathrm{pmol} / \mathrm{L} * \mathrm{~h}\right)$ & $50.4(39.7 ; 63.2) * *$ & $42.6(37.9 ; 47.2)$ \\
\hline
\end{tabular}

Data presented as median (25; 75 quartiles).

${ }^{*} P<0.05, * * P<0.001$ vs controls.

\begin{tabular}{|lr}
\hline http://www.endocrineconnections.org & ○ 2017 The authors \\
DOI: 10.1530/EC-17-0034 & Published by Bioscientifica Ltd
\end{tabular}

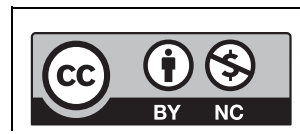

This work is licensed under a Creative Commons Attribution-NonCommercial 4.0 International License. 
GLP-1 in PCOS

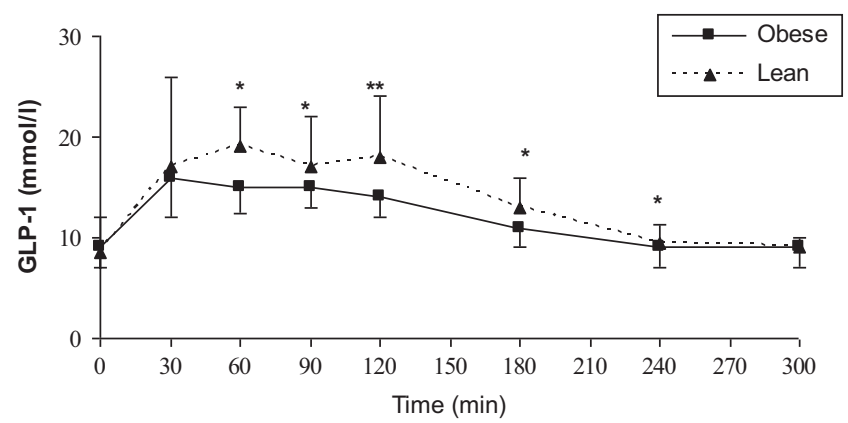

GLP-1 in obese vs. lean patients with PCOS

$*$ : $\mathrm{p}<0.05, * *: \mathrm{p}<0.001$ vs. obese patients

Figure 3

GLP-1 levels in obese and lean patients with PCOS.

unchanged despite normalized testosterone levels during treatment with OCP, which did not support an association between testosterone and GLP-1 secretion. In support of this hypothesis, total testosterone levels were unchanged during treatment with GLP-1 despite significant weight loss in patients with PCOS $(28,29)$.

We found that metformin treatment was associated with unchanged GLP-1 secretion, whereas insulin levels decreased during 5-h OGTT and the median weight loss was $3.0 \mathrm{~kg}$ (15). In contrast, Svendsen et al. reported increased GLP-1 secretion during 2-h OGTT after 8-month treatment with metformin in 22 lean and obese women with PCOS (6). Measures of insulin resistance were unchanged and no reduction in BMI was reported (6). In vitro and in vivo studies in patients with type 2 diabetes and obese non-diabetic subjects, supported that treatment with metformin could increase GLP-1 secretion directly by stimulating the GLP-1 producing cells and by decreasing soluble dipeptidyl peptidase- 4 activity and thereby inhibit GLP-1 degradation $(30,31)$. We did therefore expect increased GLP-1 levels during metformin treatment. The median changes in fasting, 2-h and 5-h AUC GLP-1 levels during metformin treatment were positive, but the present long-term study design did not allow the inclusion of a placebo group. It is possible that metformin treatment could have short-term effects on GLP-1 secretion that does not persist during long-term treatment, but more studies are needed to test this hypothesis.

We tested the hypothesis that medical treatment in PCOS could change the risk of $\mathrm{RH}$ and that the risk of $\mathrm{RH}$ could be mediated by changes in GLP-1 and/or insulin secretion. The prevalence of $\mathrm{RH}$ increased in women treated with metformin + OCP, but OCP treatment and metformin treatment alone did not affect the risk of RH. Women with $\mathrm{RH}$ after study intervention had higher insulin secretion, whereas glucose stimulated GLP-1 secretion and BMI was comparable in patients with and without RH. Increased risk of RH was seen in both lean and obese individuals. These findings supported that increased insulin secretion were the primary mediator of increased risk of RH. The power of the present study did not allow us to test the possibility that the mechanism for RH could differ between lean and obese subgroups of patients (9). We are not aware of previous studies that investigated the effect of treatment with metformin and/or OCP on the risk of RH in PCOS. The present study did not support our

Table 4 Baseline clinical and biochemical data in patients and controls.

\begin{tabular}{|c|c|c|}
\hline & $\operatorname{PCOS}(n=90)$ & Controls $(n=34)$ \\
\hline Age (years) & $28(24-32)$ & $26(22-32)$ \\
\hline Weight (kg) & $73.7(67.1 ; 85.3)$ & $71.9(67.6 ; 82.1)$ \\
\hline BMI $\left(\mathrm{kg} / \mathrm{m}^{2}\right)$ & $26.8(23.3-30.8)$ & $25.1(22.6-27.4)$ \\
\hline \multicolumn{3}{|l|}{ Fasting } \\
\hline GLP-1 (mmol/L) & $9.0(7.5 ; 10.9)$ & $8.3(7.0 ; 10.6)$ \\
\hline Insulin (pmol/L) & $71(50-95) *$ & $55(48-68)$ \\
\hline C-peptide (pmol/L) & $707(591-930) *$ & $631(561-727)$ \\
\hline HOMA (mmol/L nmol/L) & $16.1(11.7 ; 21.0)$ & $14.2(11.4 ; 16.5)$ \\
\hline \multicolumn{3}{|l|}{ OGTT } \\
\hline $2 \mathrm{~h}$ AUC GLP-1 $\left(10^{2} \mathrm{mmol} / \mathrm{L} * \mathrm{~h}\right)$ & $18.0(15.4 ; 22.7)$ & $18.1(16.1 ; 23.7)$ \\
\hline 5h AUC GLP-1 (10² $\mathrm{mmol} / \mathrm{L} * \mathrm{~h})$ & $38.6(31.7 ; 44.4)$ & $37.0(34.5 ; 46.6)$ \\
\hline $2 \mathrm{~h}$ AUC BG $\left(10^{2} \mathrm{mmol} / \mathrm{L}^{*} \mathrm{~h}\right)$ & $8.9(8.3 ; 9.8)$ & $8.6(8.3 ; 9.3)$ \\
\hline $5 \mathrm{~h}$ AUC BG $\left(10^{2} \mathrm{mmol} / \mathrm{L} * \mathrm{~h}\right)$ & $17.7(16.5 ; 19.1)$ & $18.5(17.6 ; 19.0)$ \\
\hline $2 \mathrm{~h}$ AUC insulin $\left(10^{3} \mathrm{pmol} / \mathrm{L} * \mathrm{~h}\right)$ & $41.3(30.7 ; 66.0) *$ & $34.1(22.9 ; 51.2)$ \\
\hline $5 \mathrm{~h}$ AUC insulin $\left(10^{3} \mathrm{pmol} / \mathrm{L}^{*} \mathrm{~h}\right)$ & $60.8(44.7 ; 89.9)$ * & $48.3(33.3 ; 70.6)$ \\
\hline $2 \mathrm{~h}$ AUC C-peptide $\left(10^{4} \mathrm{pmol} / \mathrm{L}^{*} \mathrm{~h}\right)$ & $27.2(22.7 ; 34.5) *$ & $25.1(20.4 ; 27.3)$ \\
\hline $5 \mathrm{~h}$ AUC C-peptide $\left(10^{4} \mathrm{pmol} / \mathrm{L}^{*} \mathrm{~h}\right)$ & $50.4(39.7 ; 63.2) * *$ & $42.6(37.9 ; 47.2)$ \\
\hline
\end{tabular}

Data presented as median (25; 75 quartiles).

${ }^{*} P<0.05, * * P<0.001$ vs controls.

http://www.endocrineconnections.org
$\begin{array}{lr}\text { DOI: } 10.1530 / E C-17-0034 & 2017 \text { The authors } \\ \end{array}$


hypothesis that weight gain during treatment with OCP was associated with increased risk of RH (32). However, insulin resistance was deteriorated during treatment with OCP as fasting and glucose-stimulated insulin levels increased. It is possible that the effects of OCP treatment on insulin and C-peptide levels were too modest to affect the risk of RH. In meta-analyses, treatment with OCP was associated with unchanged fasting insulin in PCOS (16), but fasting insulin is only a rough measure of insulin resistance (33) and different generation OCPs could have divergent effects on metabolic risk factors (34). Increased ghrelin levels during OCP treatment could be a marker of increased appetite, but previous data on ghrelin secretion during treatment with OCP in patients with PCOS were conflicting $(35,36)$. More data are therefore needed on the possible effects of different generation OCPs on metabolic risk including $\mathrm{RH}$, appetite regulation and insulin resistance in PCOS.

We found that GLP-1 secretion was comparable in patients and controls both at fasting and during 5-h OGTT and GLP-1 levels were also comparable in obese and lean subgroups of patients and weight-matched controls. Results from recent studies on GLP-1 secretion in PCOS were conflicting. The majority of studies found no significant differences in GLP-1 levels between patients with PCOS and weight-matched controls $(5,6,37)$, whereas lower GLP-1 levels in lean patients with PCOS vs weight-matched controls were reported in two studies $(4,38)$. Our findings are in agreement with the study by Svendsen et al. in 40 patients with PCOS (6), reporting comparable GLP-1 levels between patients with PCOS and controls overall and in lean and obese subgroups during 2-h OGTT, whereas less than 25 patients were included in the remaining studies $(4,5,37,38)$. Furthermore, we used up-to-date methods for the measurement of GLP-1 (22) in contrast to previous studies $(4,5,37,38)$. Comparable measures of insulin resistance between patients and controls $(4,5,6,38)$ could have affected study outcomes in previous studies. Our findings of significantly higher measures of insulin resistance in PCOS vs controls further supported that BMI is the most important predictor of GLP-1 secretion in PCOS and that PCOS itself is not associated with changed GLP-1 secretion.

The strength of the present study was the randomized controlled design. A recent publication of similar sample size reported significant changes in GLP-1 secretion during metformin treatment (6). Furthermore, up-to-date methods were applied for the measurement of GLP-1 (22). This supported that the present study had power to detect changes in GLP-1 secretion during medical treatment. A study limitation was the inclusion of relatively lean women and that the long intervention period did not allow for the inclusion of a placebo group. Normal-weight patients had high drop-out rates especially in the two treatment arms including metformin, which could lead to type 1 error, thus lack of power. $P$ values were, however, close to one, which support our conclusions. The pathogenesis of insulin resistance in PCOS is multifactorial and insulin resistance is difficult to assess by mathematical indices (39). Furthermore, there are intra-individual variations in glucose levels, which could lead to misclassification of RH (40). Our findings regarding risk of RH during medical treatment in PCOS therefore need to be reproduced in future studies.

In conclusion, the present study supported that GLP-1 levels were unchanged during medical intervention with metformin and/or OCP and increased risk of RH could be associated with increased insulin levels during medical intervention with metformin + OCP. GLP-1 secretion was predicted by BMI and not by PCOS-status.

\section{Declaration of interest}

None of the authors have any conflict of interest that could be perceived as prejudicing the impartiality of the research reported. Sandoz sponsored tablets, but were otherwise not involved in the projects' economy, planning or writing of article.

\section{Funding}

Financial grants for the studies were supported by Institute of Clinical Research, Odense University Hospital, Kolding Hospital, A P Møller's Foundation, The Novo Nordisk Foundation, The Danish Medical Association. Oral contraceptive pills and metformin tablets were sponsored by Sandoz.

\section{Author contribution statement}

D G and H M performed experiments; D G and M A conceived and planned the study; J J H contributed reagents and performed analyses; D G drafted the manuscripts; $\mathrm{H} \mathrm{M}, \mathrm{J} J \mathrm{H}$ and $\mathrm{M} \mathrm{A}$ helped writing manuscript and constructive criticism.

\section{Acknowledgements}

The authors thank Jeannette Fogh Lindegaard, Mette Brøchner Hansen, Anne Mette Hangaard, Susanne Møller Pedersen, Geraldine Rasmussen, Thon Kowall Andersen and Lene Bruus Albæk for excellent technical assistance.

\section{References}

1 Glintborg D \& Andersen M. An update on the pathogenesis, inflammation, and metabolism in hirsutism and polycystic ovary syndrome. Gynecological Endocrinology 20104 281-296. (doi:10.3109/09513590903247873)

2 Rotterdam ESHRE/ASRM-Sponsored PCOS Consensus Workshop Group. Revised 2003 consensus on diagnostic criteria and long-term

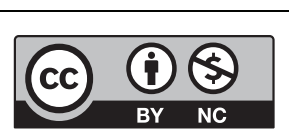

This work is licensed under a Creative Commons Attribution-NonCommercial 4.0 International License. 
health risks related to polycystic ovary syndrome. Fertility and Sterility 20041 19-25. (doi:10.1093/humrep/deh098)

3 Holst JJ. Enteroendocrine secretion of gut hormones in diabetes, obesity and after bariatric surgery. Current Opinion in Pharmacology 20136 983-988. (doi:10.1016/j.coph.2013.09.014)

4 Aydin K, Arusoglu G, Koksal G, Cinar N, Aksoy DY \& Yildiz BO. Fasting and post-prandial glucagon like peptide 1 and oral contraception in polycystic ovary syndrome. Clinical Endocrinology 20144 588-592. (doi:10.1111/cen.12468)

5 Pontikis C, Yavropoulou MP, Toulis KA, Kotsa K, Kazakos K, Papazisi A, Gotzamani-Psarakou A \& Yovos JG. The incretin effect and secretion in obese and lean women with polycystic ovary syndrome: a pilot study. Journal of Women's Health 20116 971-976. (doi:10.1089/jwh.2010.2272)

6 Svendsen PF, Nilas L, Madsbad S \& Holst JJ. Incretin hormone secretion in women with polycystic ovary syndrome: roles of obesity, insulin sensitivity, and treatment with metformin. Metabolism 2009 5 586-593. (doi:10.1016/j.metabol.2008.11.009)

7 Brun JF, Fedou C \& Mercier J. Postprandial reactive hypoglycemia. Diabetes and Metabolism 20005 337-351.

8 Altuntas Y, Bilir M, Ucak S \& Gundogdu S. Reactive hypoglycemia in lean young women with PCOS and correlations with insulin sensitivity and with beta cell function. European Journal of Obstetrics and Gynecology and Reproductive Biology 20052 198-205. (doi:10.1016/j.ejogrb.2004.07.038)

9 Mumm H, Altinok ML, Henriksen JE, Ravn P, Glintborg D \& Andersen M. Prevalence and possible mechanisms of reactive hypoglycemia in polycystic ovary syndrome. Human Reproduction 201631 1105-1112. (doi:10.1093/humrep/dew046)

10 Schmitz O, Fisker S, Orskov L, Hove KY, Nyholm B \& Moller N. Effects of hyperinsulinaemia and hypoglycaemia on circulating leptin levels in healthy lean males. Diabetes and Metabolism 1997 1 80-83.

11 Salehi M, Gastaldelli A \& D'Alessio DA. Blockade of glucagonlike peptide 1 receptor corrects postprandial hypoglycemia after gastric bypass. Gastroenterology 20143 669-680. (doi:10.1053/j.gastro.2013.11.044)

12 Glintborg D. Endocrine and metabolic characteristics in polycystic ovary syndrome. Danish Medical Journal 201663 B5232.

13 Diamanti-Kandarakis E, Kouli C, Tsianateli T \& Bergiele A. Therapeutic effects of metformin on insulin resistance and hyperandrogenism in polycystic ovary syndrome. European Journal of Endocrinology 19983 269-274. (doi:10.1530/eje.0.1380269)

14 Costello M, Shrestha B, Eden J, Sjoblom P \& Johnson N. Insulinsensitising drugs versus the combined oral contraceptive pill for hirsutism, acne and risk of diabetes, cardiovascular disease, and endometrial cancer in polycystic ovary syndrome. Cochrane Database of Systematic Reviews 20071 CD005552. (doi:10.1002/14651858.cd005552.pub2)

15 Glintborg D, Altinok ML, Mumm H, Hermann AP, Ravn P \& Andersen M. Body composition is improved during 12 months treatment with metformin alone or combined with oral contraceptives compared to treatment with oral contraceptives in polycystic ovary syndrome. Journal of Clinical Endocrinology and Metabolism 201499 2584-2591. (doi:10.1210/jc.2014-1135)

16 Halperin IJ, Kumar SS, Stroup DF \& Laredo SE. The association between the combined oral contraceptive pill and insulin resistance, dysglycemia and dyslipidemia in women with polycystic ovary syndrome: a systematic review and meta-analysis of observational studies. Human Reproduction 20111 191-201. (doi:10.1093/humrep/deq301)

17 Asarian L, Abegg K, Geary N, Schiesser M, Lutz TA \& Bueter M. Estradiol increases body weight loss and gut-peptide satiation after Roux-en-Y gastric bypass in ovariectomized rats. Gastroenterology 2012 2 325-327. (doi:10.1053/j.gastro.2012.05.008)

18 Palomba S, Falbo A, Zullo F \& Orio F Jr. Evidence-based and potential benefits of metformin in the polycystic ovary syndrome: a comprehensive review. Endocrine Reviews 20091 1-50. (doi:10.1210/er.2008-0030)

19 Schofl C, Horn R, Schill T, Schlosser HW, Muller MJ \& Brabant G. Circulating ghrelin levels in patients with polycystic ovary syndrome. Journal of Clinical Endocrinology and Metabolism 200210 4607-4610. (doi:10.1210/jc.2002-020505)

20 Morin-Papunen LC, Vauhkonen I, Koivunen RM, Ruokonen A, Martikainen HK \& Tapanainen JS. Endocrine and metabolic effects of metformin versus ethinyl estradiol-cyproterone acetate in obese women with polycystic ovary syndrome: a randomized study. Journal of Clinical Endocrinology and Metabolism 20009 3161-3168. (doi:10.1210/jc.85.9.3161)

21 Morin-Papunen L, Vauhkonen I, Koivunen R, Ruokonen A, Martikainen H \& Tapanainen JS. Metformin versus ethinyl estradiol-cyproterone acetate in the treatment of nonobese women with polycystic ovary syndrome: a randomized study. Journal of Clinical Endocrinology and Metabolism 2003 148-156. (doi:10.1210/jc.2002-020997)

22 Kuhre RE, Wewer Albrechtsen NJ, Hartmann B, Deacon CF \& Holst JJ. Measurement of the incretin hormones: glucagonlike peptide- 1 and glucose-dependent insulinotropic peptide. Journal of Diabetes and its Complications 201529 445-450. (doi:10.1016/j.jdiacomp.2014.12.006)

23 Orskov C, Rabenhoj L, Wettergren A, Kofod H \& Holst JJ. Tissue and plasma concentrations of amidated and glycine-extended glucagon-like peptide I in humans. Diabetes 19944 535-539. (doi:10.2337/diab.43.4.535)

24 Lykkesfeldt G, Bennett P, Lykkesfeldt AE, Micic S, Moller S \& Svenstrup B. Abnormal androgen and oestrogen metabolism in men with steroid sulphatase deficiency and recessive X-linked ichthyosis. Clinical Endocrinology 19854 385-393. (doi:10.1111/j.1365-2265.1985.tb01096.x)

25 Nielsen TL, Hagen C, Wraae K, Brixen K, Petersen PH, Haug E, Larsen $\mathrm{R} \&$ Andersen M. Visceral and subcutaneous adipose tissue assessed by magnetic resonance imaging in relation to circulating androgens, sex hormone-binding globulin, and luteinizing hormone in young men. Journal of Clinical Endocrinology and Metabolism 20077 2696-2705. (doi:10.1210/jc.2006-1847)

26 Outeirino-Iglesias V, Romani-Perez M, Gonzalez-Matias LC, Vigo E \& Mallo F. GLP-1 increases preovulatory LH source and the number of mature follicles, as well as synchronizing the onset of puberty in female rats. Endocrinology $2015114226-4237$. (doi:10.1210/en.2014-1978)

27 Morales AJ, Laughlin GA, Butzow T, Maheshwari H, Baumann G \& Yen SS. Insulin, somatotropic, and luteinizing hormone axes in lean and obese women with polycystic ovary syndrome: common and distinct features. Journal of Clinical Endocrinology and Metabolism 1996 8 2854-2864. (doi:10.1210/jc.81.8.2854)

28 Kahal H, Abouda G, Rigby AS, Coady AM, Kilpatrick ES \& Atkin SL. Glucagon-like peptide-1 analogue, liraglutide, improves liver fibrosis markers in obese women with polycystic ovary syndrome and nonalcoholic fatty liver disease. Clinical Endocrinology 20144 523-528. (doi:10.1111/cen.12369)

29 Nylander M, Frossing S, Kistorp C, Faber J \& Skouby SO. Liraglutide in polycystic ovary syndrome: a randomized trial, investigating effects on thrombogenic potential. Endocrine Connections 20172 89-99. (doi:10.1530/EC-16-0113)

30 Mannucci E, Ognibene A, Cremasco F, Bardini G, Mencucci A, Pierazzuoli E, Ciani S, Messeri G \& Rotella CM. Effect of metformin on glucagon-like peptide 1 (GLP-1) and leptin levels in obese nondiabetic subjects. Diabetes Care 20013 489-494. (doi:10.2337/diacare.24.3.489)

31 Kappe C, Patrone C, Holst JJ, Zhang Q \& Sjoholm A. Metformin protects against lipoapoptosis and enhances GLP-1 secretion from GLP-1-producing cells. Journal of Gastroenterology 20133 322-332. (doi:10.1007/s00535-012-0637-5) 
32 Odegaard JI \& Chawla A. Pleiotropic actions of insulin resistance and inflammation in metabolic homeostasis. Science 20136116 172-177. (doi:10.1126/science.1230721)

33 Diamanti-Kandarakis E \& Dunaif A. Insulin resistance and the polycystic ovary syndrome revisited: an update on mechanisms and implications. Endocrine Reviews 20126 981-1030. (doi:10.1210/er.2011-1034)

34 Kriplani A, Periyasamy AJ, Agarwal N, Kulshrestha V, Kumar A \& Ammini AC. Effect of oral contraceptive containing ethinyl estradiol combined with drospirenone vs. desogestre on clinical and biochemical parameters in patients with polycystic ovary syndrome. Contraception 20102 139-146. (doi:10.1016/j.contraception.2010.02.009)

35 Arusoglu G, Koksal G, Cinar N, Tapan S, Aksoy DY \& Yildiz BO. Basal and meal-stimulated ghrelin, PYY, CCK levels and satiety in lean women with polycystic ovary syndrome: effect of low-dose ora contraceptive. Journal of Clinical Endocrinology and Metabolism 2013 11 4475-4482. (doi:10.1210/jc.2013-1526)

36 Sagsoz N, Orbak Z, Noyan V, Yucel A, Ucar B \& Yildiz L. The effects of oral contraceptives including low-dose estrogen and drospirenone on the concentration of leptin and ghrelin in polycystic ovary syndrome. Fertility and Sterility 20092 660-666. (doi:10.1016/j.fertnstert.2008.07.008)

37 Gama R, Norris F, Wright J, Morgan L, Hampton S, Watkins S \& Marks V. The entero-insular axis in polycystic ovarian syndrome. Annals of Clinical Biochemistry 199633 190-195. (doi:10.1177/00045632960330 0303)

38 Vrbikova J, Hill M, Bendlova B, Grimmichova T, Dvorakova K, Vondra $\mathrm{K} \&$ Pacini G. Incretin levels in polycystic ovary syndrome. European Journal of Endocrinology 20082 121-127. (doi:10.1530/EJE-08-0097)

39 Diamanti-Kandarakis E, Kouli C, Alexandraki K \& Spina G. Failure of mathematical indices to accurately assess insulin resistance in lean, overweight, or obese women with polycystic ovary syndrome. Journal of Clinical Endocrinology and Metabolism 20043 1273-1276. (doi:10.1210/jc.2003-031205)

40 Schousboe K, Henriksen JE, Kyvik KO, Sorensen TI \& Hyltoft PP. Reproducibility of S-insulin and B-glucose responses in two identical oral glucose tolerance tests. Scandinavian Journal of Clinical and Laboratory Investigation 20028 623-630. (doi:10.1080/003655102764654358)

Received in final form 4 April 2017

Accepted 21 April 2017

Accepted Preprint published online 21 April 2017 http://www.endocrineconnections.org DOI: 10.1530/EC-17-0034
C 2017 The authors Published by Bioscientifica Ltd

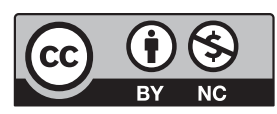

This work is licensed under a Creative Commons Attribution-NonCommercial 4.0 International License. 